\title{
Juvenile Osteochondrosis
}

National Cancer Institute

\section{Source}

National Cancer Institute. Juvenile Osteochondrosis. NCI Thesaurus. Code C35313.

Defective bone growth that affects the growth centers of bone in children. 